To appear as a chapter in the book:

P. Karoly \& G. Crombez (Eds.), Motivational perspectives on chronic pain: Theory, research, and practice. Oxford University Press.

\title{
A motivational perspective on coping with pain
}

\author{
Stefaan Van Damme ${ }^{1, *}$ and Geert Crombez ${ }^{1}$
}

${ }^{1}$ Department of Experimental-Clinical and Health Psychology, Ghent University, Belgium

Number of text pages: 44

Number of tables: 0

Number of figures: 1

*Corresponding author

Address: Henri Dunantlaan 2, 9000 Ghent, Belgium

Tel.: +32-9-264.91.49; Fax: +32-9-264.64.89

E-mail: Stefaan.Vandamme@UGent.be 


\begin{abstract}
Coping is one of the most commonly used concepts in the pain literature. Despite its popularity, it remains a broad and confusing concept that is often vaguely defined and poorly operationalized. In this chapter, we present a motivational perspective on coping that may help advance the field. Building upon a long tradition of self-regulation and goal theories, we present a motivational model of coping with pain. This model starts from the idea that pain's interference with goal pursuit elicits negative affect, which in turn activates coping responses that may then proceed along 3 possible pathways: goal persistence, problem-solving, or goal adjustment. We describe and illustrate these pathways, and argue that all three could be either adaptive or maladaptive depending upon the nature of the context. Next, we recast several traditional pain coping concepts, such as pain catastrophizing, fear-avoidance, endurance, pain-related attention, and acceptance, within this motivational perspective. We also discuss potential implications of adopting our motivational account of pain coping for clinical interventions such as exposure, attention management, and acceptance and commitment therapy. We also explore the possibility of adding implementation intention and coping planning techniques to existing pain treatments. Keywords: Pain; Coping; self-regulation; goals; motivation; problem-solving
\end{abstract}




\section{Introduction}

"Coping" is undoubtedly one of the most commonly discussed psychological concepts in the pain literature. Despite its popularity among researchers as well as clinicians, it remains a broad and even confusing concept that is often vaguely defined and poorly operationalized. In this chapter, we present a motivational perspective on coping that may be crucial in overcoming these conceptual and operational issues. We start by looking back at the origins of the coping concept, and discuss its appeal in the domain of chronic pain (section 2). Next, we briefly review the use of the coping concept in the pain literature, and specifically we discuss traditional taxonomies and classifications of pain coping strategies. We discuss how this traditional approach has been criticized, and argue that a motivational or self-regulation perspective on coping may advance the field (section 3). Next, we review self-regulation and goal theories and concepts that may help shaping a motivational reformulation of coping with pain (section 4). Subsequently, we present a motivational model of coping with pain (section 5), and recast several traditional pain coping concepts within this motivational perspective (section 6). Finally, we discuss potential implications of adopting our motivational account for clinical interventions that are typically directed at improving patients' skills for coping with pain (section 7).

\section{The appeal of coping in the pain field}

To address why coping is such a popular concept in the pain field, it may be helpful to go back to the origin of the coping concept. While the term coping already started to emerge in psychological literature in the late 1960s, its rise in popularity really began as the result of theoretical advancements in the stress literature (Coyne \& Racioppo, 2000). In their transactional model, Lazarus and his colleagues (Lazarus \& Folkman, 1984; Lazarus \& Launier, 1978) argued 
that stress involves a transaction between a person and his or her environment, and that a stress response is elicited if the person appraises a certain event in the environment as taxing or exceeding his or her resources. Lazarus differentiated between two forms of appraisals. Primary appraisal refers to the person initially identifying an event as irrelevant, benign-positive, or stressful. Secondary appraisal involves the person's appraisal of the available options and resources to cope with events that are evaluated as threatening or challenging. When resources are viewed as insufficient, the person is likely to experience the situation as stressful. Coping then consists of the strategies that individuals use to respond to stressful situations. More specifically, coping refers to the cognitive and behavioral efforts that a person engages in to manage the internal and external demands of a situation that is appraised as stressful (Folkman, Lazarus, Gruen, \& DeLongis, 1986).

It is not hard to see why the concept of coping has held such a prominent place in the field of pain. Pain itself is an archetypical stressor: i.e., it is an aversive and threatening experience, and because it is an evolutionary signal of bodily harm, pain urges the interruption of current behavior and the promotion of self-protective action (Eccleston \& Crombez, 1999). Moreover, pain disturbs normal functioning and interferes with the everyday tasks of life (Karoly \& Ruehlman, 2007); and when pain becomes chronic, it may threaten the viability of individuals' life goals, which provokes the associated stresses of anxiety, depression and identity confusion (Morley, Davies, \& Barton, 2005). Consider, for example, the three patients described in box 13.1. Louise, Marc, and Ann all suffer from pain that interferes with their daily life and personal goals. It therefore makes sense to assume that coping plays a crucial role in their successful adaptation to pain. This is exactly the reason why clinicians often seek to develop interventions to enhance and improve patients' coping strategies, both in the context of therapy and self- 
management. Of course, this perspective presumes that we know which coping responses are adaptive and which ones are not. As we discuss further on, a distinction between adaptive and maladaptive coping is less evident than often assumed. In what follows, we will explore how coping strategies have been classified and what we know about the effectiveness of different ways to cope with pain.

\section{INSERT BOX 13.1 ABOUT HERE}

\section{The rise and fall of coping research}

There are numerous ways in which persons may respond to stressful situations. Given the myriad possible ways of coping, there have been several attempts at developing classification systems. Lazarus and Folkman (1984) distinguish two categories of coping responses. Problemfocused coping involves attempts to act to either reduce or to eliminate the stressor (e.g., acting to solve a problem, learning new skills). Emotion-focused coping involves attempts to regulate the emotions evoked by the stressor (e.g., seeking distraction). Roth and Cohen (1986) contrast approach coping, involving confronting the problem, gathering information, and taking direct action, with avoidance coping, referring to minimizing the importance of the stressful event. Although these classifications are probably the most well-known, there are numerous other coping scales and category systems, sometimes identifying dozens of different coping responses. A review of these coping classification systems resulted in up to 400 different labels spread across over 100 systems (Skinner, Edge, Altman, \& Sherwood, 2003). Given the obvious lack of consistency and consensus in the categorization and assessment of coping styles, obtaining a cohesive picture of the structure of coping is difficult to achieve. This problem has slowed 
progress in the field. Nevertheless, researchers continued in their attempts to differentiate between adaptive and maladaptive coping strategies. Overall, there is a widespread stereotypical belief that action-oriented, problem-focused coping may be more adaptive than emotion-focused and passive coping (Hobfoll, 1988).

These ideas have permeated the pain literature (Van Damme, Crombez, \& Eccleston, 2008), and several pain coping assessment instruments have adopted similar classifications. In line with Lazarus and Folkman (1984), the Daily Pain Coping Inventory (Affleck, Tennen, Keefe, Lefebvre, Kashikar-Zuck, Wright, Starr, \& Caldwell, 1999) distinguishes between 'problem-focused' and 'emotion-focused' coping. Problem-focused coping refers to direct attempts to deal with the pain or to solve the pain problem (e.g. "Did something specific to try to reduce the pain"). Emotion-focused coping strategies deal with the emotional responses and stress elicted by pain pain (e.g. "Sought emotional support from loved ones, friends, or professionals concerning my pain"). The Pain Coping Questionnaire (Reid, Golbert, \& McGrath, 1998) follows the dichotomy between 'approach' versus 'avoidance' coping as proposed by Roth and Cohen (1986). The approach scale measures direct attempts to deal with the pain and the use of active methods to regulate feelings when in pain, thus containing elements of both problemfocused and emotion-focused coping. The scale is further divided into information seeking, problem solving, seeking social support, and positive self-statements subscales. Avoidance coping describes strategies of engaging efforts away from pain, and distinguishes between problem-focused and emotion-focused avoidance. The problem-focused avoidance scale measures the attempts to disengage from the pain, and consists of positive self-statements, behavioral distraction, and cognitive distraction subscales. The emotion-focused avoidance scale measures strategies in which emotions are freely expressed, and strategies that reflect lack of 
effort in regulating feelings when in pain. It is comprised of externalizing and internalizing (catastrophizing) subscales. The Vanderbilt Pain Management Inventory (Brown \& Nicassio, 1987) distinguishes between 'active' and 'passive' coping. Active coping refers to strategies used to control pain or to function despite pain (e.g. "Try to distract yourself from the pain"). Passive coping is related to withdrawing and surrendering control over pain (e.g. "Take medicine to see whether the pain goes off").

There is the overall idea that in chronic pain, active, problem-oriented, and approach coping strategies are likely to be adaptive, whereas passive, emotion-oriented, and avoidance coping strategies are likely to be maladaptive. This view seems to be supported by numerous empirical studies (e.g., Carroll, Cassidy, \& Cote, 2006; López-Martínez, Esteve-Zaragaza, \& Ramírez-Maestre, 2008). Some studies support the beneficial effects of perceived control over pain (Buckelew et al., 1994; Jensen \& Karoly, 1991). Conversely, a perceived lack of control may promote feelings of helplessness and may be associated with unfavorable adaptation to pain (Koleck, Mazaux, Rascle, \& Bruchon-Schweitzer, 2006; Nicassio, Schuman, Radojevic, \& Weisman, 1999).

Although it is intuitively appealing to consider active, problem-focused, and approach coping strategies as adaptive, there are several problems with such a structural approach. First, classification systems commonly focus on single functions (e.g., problem vs. emotion focused) or topographic distinctions (e.g., approach vs. avoidance, or active vs. passive). However, it has been argued that these are not adequate categories because all ways of coping are multidimensional and may serve different functions (Skinner et al., 2003). Apparently distinct strategies can be classified as similar or as disimilar depending on context. Consider, for example, the taking of pain medication. In some situations, this is a passive and avoidant pain 
management strategy, specifically when medication is used to escape the aversive experience of pain. Yet in others it can be considered active and problem focused, specifically when it is used to allow continuation of goal pursuit. Second, the value of coping strategies in predicting outcomes may be inflated by virtue of how they are measured (Steed, 1998). Items of active and problem-focused coping are typically formulated in a positive and constructive way, whereas items for passive and emotion-focused coping strategies are often negatively toned (Skinner et al., 2003). For example, in the Vanderbilt Pain Management Inventory (Brown \& Nicassio, 1987), active coping items are formulated as "Although it hurts, I just keep on going" or "No matter how bad it gets, I know I can handle it", whereas passive coping items typically appear as "I feel my life isn't worth living" or "I feel I can't stand it anymore". Such items also show strong content overlap with outcome measures typically used to assess adjustment, such as disability and depression. Third, after decades of research, no specific repertoire of coping strategies has emerged as clearly more effective than any other for chronic pain patients (McCracken \& Eccleston, 2003). In fact, for several coping strategies empirical evidence exists for both beneficial and adverse effects on pain and patient functioning. For example, research focusing on the strategy of pain control has yielded inconclusive evidence. Attempting to control or to find a solution for pain is generally associated with better patient functioning (Keefe, Rumble, Scipio, Giordano, \& Perri, 2004), but may have negative consequences when actual control is difficult to achieve (Crombez, Eccleston, Van Hamme, \& De Vlieger, 2008b). Moreover, an exclusive focus on pain control may, in some circumstances, also lead to greater suffering and disability (Aldrich, Eccleston, \& Crombez, 2000; Eccleston \& Crombez, 2007). Similarly, when experiencing an acute episode of non-specific back pain, maintaining a certain level of physical activity despite pain is generally considered more adaptive than excessive avoidance (Vlaeyen \& Linton, 2000). 
Nevertheless, excessive task persistence, meaning that one over-engages in goal pursuit and ignores pain at all costs may result in physiological damage and put one at risk for developing chronic pain problems (Hasenbring \& Verbunt, 2010). An challenge for theory and clinic practice is differentiating between adaptive and maladaptive persistence of physical activity.

As shown above, a mere descriptive or structural approach to classifying coping, is problematic. Coping in the context of chronic pain, we argue, should be considered from a functional perspective. In their seminal work on coping, Skinner et al. (2003) identified three overarching and adaptive functions that coping may aim to achieve. The first adaptive function is coordinating actions with contingencies in the environment. Examples of coping responses related to this process are problem solving (i.e., adjusting actions to be effective), and escape (i.e., escaping a non-contingent environment). The second adaptive function is coordinating preferences with available options. Examples are accommodation (i.e., flexibly adjusting preferences to options and constraints) and submission (i.e., giving up preferences). The third function, which is often overlooked in the coping literature, is coordinating with available social resources. Examples are support seeking (i.e., using available social resources), and isolation (i.e., withdrawing from an unsupportive social context). It is akin the "tend and befriend" pattern of Taylor and colleagues (2010). This function reminds us that individuals do not always cope to solve a problem, but may equally well want to (re)establish their social belongingness.

From a functional approach the primary aim of all coping responses is interacting with the stressor in order to return to continue with daily life. This brings Lazarus' "motivational principle" in mind, stating that "Emotions are first and foremost reactions to the fate of active goals in everyday encounters of living and in our lives overall” (Lazarus, 1991, p.92). 
It is important to keep in mind that coping may refer to any cognitive or behavioral response to threat, regardless of its success (Tunks \& Bellissimo, 1988). In other words, although coping responses are always related to adaptive processes, they do not necessarily lead to a lasting solution or to an improvement of the specific problem encountered. For instance, some responses such as excessive avoidance may result in short-term pain relief, but at the same time they may increase the risk of exacerbation of chronic pain (Vlaeyen \& Linton, 2000). Thus, whereas coping responses can be aimed at correcting or solving problems, they might also help people to change how they appraise their problems or help them to escape or avoid the problematic situation. As such, coping can be best conceived as a self-regulation process. In the next section, we will discuss self-regulation and goal theories that may help increase our understanding of the processes involved in coping with pain (see also Chapter 1 of the present volume).

\section{Recasting coping within self-regulation and goal theories}

In this section, we recast the coping construct within theories and models that address goals and the process of self-regulation. We start from the basic tenet that behavior is the result of the organizing power of goals in a broad array of domains (e.g., social, work-related, health). Self-regulation has been conceptualized as involving the processes by which one attempts to gain control over behavior, thoughts, feelings, desires, and actions in the service of goal attainment (Carver \& Scheier, 1998; de Ridder \& de Wit, 2006; Karoly, 1993; Vohs \& Baumeister, 2004; see also Chapter 1 of this volume). An important aspect of self-regulation is how people modulate negative states, adversities or setbacks in the process of goal striving, which is clearly related to the idea of coping. Several theories and models may be helpful for developing a 
motivational account of coping with pain. In what follows we briefly describe some of these models.

\subsection{Cybernetic control theory of self-regulation}

The cybernetic control theory perspective on self-regulation (e.g., Carver \& Scheier, $1982,1998)$ starts from the assumption that goals are central to successful adaptation and that people behave in ways that are aimed at attaining their goals. Following earlier engineering models of machine-based self-steering, Carver and Scheier described a negative feedbackcentered system that monitors progress towards the attainment of a goal. Whenever a discrepancy is detected between the current state and the goal, people adjust their behavior in ways designed to reduce this discrepancy. Central to Carver and Scheier's version of a cybernetic model is the role of affect as a reflection of goal progress. Regarding coping, negative affect is of special interest, because it signals that goal progress is not going well. Negative affect is said to promote either increasing effort, or disengagement, the latter occurring when the person's expectancy of being able to reduce the sensed discrepancy is unfavorable. Such disengagement may involve scaling back work on the goal to make it less demanding, or abandoning the goal so that other goals can be taken up. Although this theory does not explicitly mention the concept of coping, similarities to the stress-coping literature clearly exist, such as the person-environment transactional model noted earlier (Lazarus \& Folkman, 1984).

Recently, researchers have applied cybernetic control theory concepts to the ways people cope with goals that, for various reasons, have become unattainable (Rasmussen, Wrosch, Scheier, \& Carver, 2006). They argue that, in such cases, goal adjustment may play an important role in enhancing quality of life. Specifically, individuals may be able to avoid the negative consequences resulting from the experience of unattainable goals if they engage in adaptive self- 
regulation. Two processes are involved in such self-regulation. First, individuals need to disengage from unattainable goals, a process that requires withdrawing effort and commitment from pursuing goals that are deemed unachievable (Wrosch, Scheier, Miller, Schulz, \& Carver, 2003). Second, individuals need to re-engage goal-directed effort by identifying, and then committing themselves to the pursuit of alternative goals. Both processes are deemed adaptive because they ostensibly protect the individual against the negative consequences of repeated goal failure while maintaining a sense of purpose in life (Wrosch et al., 2003). The unattainability of goals may have several possible sources. For example, illness and health problems, such as chronic pain, can be important sources of goal interference and even goal conflict (see chapter 11), though the theory does not explicitly address these potential sources.

\subsection{Self-regulatory theory of illness behavior}

A theory in which coping is explicitly addressed and directly applied to health and illness is the self-regulatory model of illness behavior, developed by Leventhal and colleagues (e.g., Cameron \& Leventhal, 2003). The central idea in this model is that individuals are active problem-solvers who are motivated to re-establish a state of normality or a return to the status quo. Problem-solving is assumed to occur in three stages: (1) interpretation, (2) coping, and (3) appraisal. The first stage, interpretation, refers to assigning meaning to the problem. Individuals develop their own understanding of an illness by forming a set of cognitions, which can be ordered along 5 dimensions (Leventhal, Meyer, \& Nerenz, 1980): identity (the label given to the illness and the symptoms experienced), cause (perceived cause of the illness), time line (is the illness acute or chronic?), consequences (possible effects of the illness on physical, emotional, and social aspects of life), and curability and controllability (can the illness be treated and cured, and is it controllable by oneself or others?). Cognitive representations are typically based on past 
illness experiences, social influences, and interactions with health-care providers. The second stage in the self-regulatory model is the development and identification of suitable coping strategies, a process that is typically influenced by the cognitive representations of illness. The third stage consists of evaluating the effectiveness of the coping strategy used, and determining whether to continue with this strategy or opt for an alternative strategy.

Although the model is self-regulatory in its focus, because the different components interact to achieve balance or normality when the normal state is disrupted by illness, it focuses exclusively on health goals, and does not make explicit how other life goals are affected by illness or how individuals respond to such goal interference.

\subsection{Dual process model of coping}

The Dual Process Model was originally developed to understand adaptation in response to ageing-related problems (Brandstaedter \& Renner, 1990; Brandstaedter \& Rothermund, 2002). It describes how, as individuals get older, they naturally lower their efforts to solve encountered problems that block their functioning and valuable life goals. Instead, with increasing age, individuals' motivation to adapt their goals to physical restraints (for example, because of health issues) heightens. The central assumption of the model is that perceived or anticipated goal discrepancies lead to negative affect and activate self-regulatory processes. The model distinguishes between two fundamentally different regulatory modes, namely "assimilation" and "accommodation". Assimilative coping refers to persistent goal pursuit wherein the individual attempts to modify the current situation to fit the pursued goal, and to overcome the problem by increasing effort. Accommodative coping refers to adjusting the goal to fit experienced constraints, also resulting in reduced discrepancies between the pursued goal and the current situation. Accommodation can involve reducing the importance of the disturbed goal, and 
thereby avoiding escalation of one's commitment toward unrewarding goal pursuit. It may also involve positively reappraising the current situation, and thereby alleviating the negative emotional impact of goal failure. Of note, Brandstadter states that accommodation is not an intentional process. It often emerges as a consequence of low mood. Importantly, the dual process model also specifies the factors that influence whether assimilative or accommodative coping will prevail. First, assimilative coping will depend on perceived control over goal attainment. When perceived control is low (for example, because of the limited availability of action resources), assimilative responses will decline and the accommodative mode will become activated. Second, when the threatened goal holds a central place in the individual's goal hierarchy or identity, assimilative coping is likely to dominate, and accommodative tendencies will be inhibited because disengaging from such a goal would be very difficult and painful. Although assimilative and accommodative coping modes inhibit each other and cannot operate simultaneously, they can become activated sequentially. For example, after repeated unsuccessful assimilative coping attempts, the individual may start to experience hopelessness and a low mood, and enter an intermediate stage of disorganization and disorientation. This stage may provide ground for an accommodative reorientation. Because the dual process model is rather reactive regarding experienced goal interference, it may also be worthwhile to explore theories in which coping is considered a proactive strategy. This is the case in behavioral enaction theories.

\subsection{Behavioral enaction theories}

Contemporary motivational theories have become increasingly focused on processes involved in the maintenance of action to achieve one's goals (Abraham \& Sheeran, 2000). These models do not only address goal setting, but also describe important processes involved in goal striving. For example, the health action process approach (HAPA; Schwarzer, 2008). is designed 
as a sequence of two continuous self-regulatory processes, a goal-setting phase (motivation) and a goal-pursuit phase (volition). Within this second self-regulatory phase, the key concept is planning, which can be further divided into action planning and coping planning. Action planning specifies the when, where, and how of an intended action. Coping planning refers to the anticipation of barriers and the design of alternative actions that help the individual to attain his or her goals despite the distractors. Thus, in line with previously described theories, coping is here characterized as a response to anticipated goal disturbance, with the aim of maintaining goal-directed behavior.

Specific emphasis within this framework is on action planning interventions. Gollwitzer (1996) introduced the idea of implementation intentions. These are if-then plans that specify when, where and how a goal-directed action is to be initiated (Gollwitzer, 1999). The formation of implementation intentions is assumed to delegate control over goal-directed action to the situation, so that the behavior depends less on willpower or self-control. Recently, it has been suggested that using pain as a cue (if) to induce task goal pursuit (then) significantly reduced pain-related avoidance in an experimental context (Karsdorp, Geenen, Kroese, \& Vlaeyen, 2016). Coping planning interventions are slightly more complex, and link situational cues related to undesired behaviors (if) with cognitive or behavioral coping responses aimed at inhibiting the undesired responses, or prioritizing the desired responses (then) (Sniehotta, Scholz, \& Schwarzer, 2006). The if-condition in coping planning specifies situations, inner states, or behaviors that are conflicting or incongruent with the target behavior (Sniehotta, Schwarzer, Scholz, \& Schüz, 2005). The then-condition is a coping response rather than a directly goal-related behavior. Coping plans shield goal-directed behavior by aiming to manage the risky situation rather than to directly initiate goal-directed action. The principles underlying the formation of implementation 
intentions and coping planning have already been successfully applied in the context of selfregulation interventions for chronic pain patients. For example, in a study by Christiansen, Oettingen, Dahme, and Klinger (2010), a total of 75 chronic back pain patients were either allocated to a control group receiving treatment as usual, i.e., a 3-week standard outpatient back pain program, or to an intervention group receiving treatment as usual plus a short (one hour) goal-pursuit intervention. In the goal-pursuit intervention, the patients were asked to identify pain-related obstacles (such as negative beliefs) when setting behavioral goals related to improving physical capacity, and then were guided to generate problem-solving techniques to overcome these obstacles. Patients formulated implementation intentions such as "If I am afraid of hurting myself, then I will remember that movement is good against pain". Physical capacity, both self-reported and objectively measured, increased significantly more in the intervention group than in the control group, both 3 weeks and 3 months after completion of the program.

\section{Toward a motivational account of coping with pain}

It is essential that researchers and clinicians understand the broad, motivational context of behavior. Indeed, patients cope with chronic pain for a reason, namely to pursue a meaningful and valued life. An important aspect of self-regulation is how people cope with negative states, adversities, or setbacks in the process of goal striving. Pain typically represents such negative state, and chronic pain is often perceived as a barrier to the pursuit of valued goals (Affleck, Tennen, Zautra, Urrows, Abeles, \& Karoly, 2001). It is therefore important that we endeavor to understand how people struggle to make sense of unwanted experiences, and how they avoid, adapt, or alter the perceived causes of those experiences. Building on the self-regulation theories described in the previous section, we propose a motivational model of coping with pain. Within 
this self-regulation perspective, pain coping responses are no longer viewed as the direct consequence of how pain is perceived or interpreted, but rather as the result of the self-regulation of current goals in the context of pain. Our motivational re-casting of coping with pain aims to increase our understanding of how individuals respond to goal interference by pain. The model is shown in figure 13.1. It begins with the presence of pain resulting in actual or expected discrepancy emerges between the outcome of goal pursuit and the desired outcome of behavior. This discrepancy results in negative affect, which triggers three possible coping responses. These pathways are indicated in figure 1, and consist of (1) goal persistence, (2) problem-solving, and (3) goal adjustment. We will next describe each of these pathways in greater detail. (1) Goal persistence. When an active goal is threatened by pain, individuals may try harder and increase their effort to accomplish the goal. Patients are often motivated to stay committed to earlier (pre-pain) life goals and performance standards, which is a typical example of assimilative coping as specified in the dual process model of coping (Van Damme et al., 2008). This process is nicely illustrated in the case of Louise (see box 13.1). When her work suffers because of pain interference, she compensates for the lost time by working extra hours. On a cognitive level, when pain arises as an obstacle during goal implementation, this induces an increase in shielding and focusing tendencies, a mobilization of effort, and a reactive increase in the attractiveness of the goal so as to compensate for the increased effort and perceived costs (Brandstaedter \& Rothermund, 2002). Goal persistence then is characterized by increased recruitment of executive control and top-down processing to protect goal-directed behaviour. For example, attention will be focused on goal-relevant information, whereas distractors such as pain will be inhibited (Van Damme, Legrain, Vogt, \& Crombez, 2010; see also chapter 7). Indeed, experimental research has shown that pursuing a valued goal reduces attentional bias towards pain-related information 
(Schrooten, Van Damme, Crombez, Peters, Vogt, \& Vlaeyen, 2012), perception of pain (Verhoeven, Crombez, Eccleston, Van Ryckeghem, Morley, \& Van Damme, 2010), and avoidance behavior (Claes, Kairos, Meulders, Crombez, \& Vlaeyen, 2014; Van Damme, Van Ryckeghem, Wyffels, Van Hulle, \& Crombez, 2012).

(2) Problem-solving. In case of repeated goal failure, searching for a solution for pain may become a salient goal, which may even temporarily replace the threatened goal. In that case, individuals may shift their effort towards attempting to solve or control the pain problem. Attempts to diminish the impact of pain in order to reengage in "pre-pain" activities and life goals could also be considered a manifestation of assimilative coping, in line with the dual process model (Van Damme et al., 2008). Increased accessibility of negative information may occur, and effort and attention may become narrowly focused on the goal of pain control (Eccleston \& Crombez, 2007; Van Damme et al., 2008). Because the problem of pain is typically framed as biomedical, an external solution is usually favored (Eccleston \& Crombez, 2007). Different behaviors (e.g., bed rest, seeking over-the-counter medication) may occur, and may depend on individual differences in such general factors as habits and skills, and on specific factors such as beliefs about the origins of pain and the perceived controllability of pain. Often problem-solving will be informed by beliefs about the origins and the controllability of pain; but it is equally possible that attempts to solve pain are fueled by the value of the goals that are being blocked by pain. This is the case for Marc, who keeps over-using pain medication to be able to properly do his job as a teacher.

(3) Goal adjustment. Repeated failure in achieving control over pain and in attaining valued goals may create the foundation for disengagement from the unattainable goal. In line with the "accommodative route" described in the dual process model, such disengagement may involve an 
increased availability of cognitions that devalue the blocked goal and enhance positive reappraisal of the situation (Brandstaedter \& Rothermund, 2002). Either effort may be maintained at the present level, allowing the current goal to remain in place but at a lower goal standard (reduced aspiration allowing for lower performance), or effort may be reduced, resulting in the current goal being abandoned (disengagement) and replaced by an alternative goal. Ann, for example, attempts to disengage from one goal (spinning with friends) and to reengage with an alternative goal, namely walking with her friends (see box 13.1). Cognitively, the mode of attention shifts from narrowly focused and top-down towards more holistic, broad-based and bottom-up, allowing activation of alternative goals that may be more feasible and less affected by pain. Possible coping responses are acceptance, priority setting, and cognitive restructuring.

\section{INSERT FIGURE 1 ABOUT HERE}

Coping with chronic pain is recast as the attempt to pursue valuable personal goals and activities (see also Van Damme \& Kindermans, 2015). Starting with the interruption of behavior by pain, individuals appraise the importance of the interrupted activity and the nature of the obstacle. When the value of the blocked goal is high, the default option of the goal regulator is increasing effort in the service of goal persistence. This will be especially the case if expectancy is high that the goal can be successfully attained. However, goal persistence comes with costs stemming from the increased effort required to research goal standards. When there is continuing interference by pain, problem-solving attempts may be triggered, which may then temporarily become the dominant goal (Eccleston \& Crombez, 2007). Individuals are most likely to engage in problem solving when they perceive the problem of pain as controllable, either by themselves 
or by others (e.g., health care providers). Because individuals do not easily disengage from important goals, this will only be the case after repeated failure and low perceived control. Whether coping in a certain situation is adaptive or maladaptive depends upon the match between a people's appraisal of their abilities and their real abilities, the accuracy of their appraisal of the threat, and their ability to switch to a different coping approach if their chosen strategy fails. It may also depend on the function of the coping response. For example, if the coping response is aimed at withdrawal from an unhelpful social environment (which is one of the functions of coping, see Skinner et al., 2006), then this strategy may not help the person deal with the pain itself. Therefore, neither coping response is 'de facto' the "right approach" to the problem of chronic pain. We will illustrate this with several examples.

Goal persistence is adaptive to some extent, but may become maladaptive. At first, it may seem adaptive to prevent interference by pain and to continue with one's activities. However, excessive activity persistence despite pain may also carry costs, such as the risk of enhancing the pain (Hasenbring, Plaas, Fishbein, \& Willburger, 2006). For instance, it has been argued that excessive task persistence despite severe pain has adverse consequences for long-term adjustment (Hasenbring \& Verbunt, 2010). When we look back at the case of Louise, she would definitely be at risk for developing a pattern of excessive persistence, possibly worsening her pain problem in the long term.

Active attempts to control pain may be effective in acute pain situations and when a solution is available (Keefe et al., 2004). But increased effort towards pain control may also incur costs. Intake of medication, for instance, may result in overuse which has obvious costs (Lauwerier, Paemeleire, Van Damme, Goubert, \& Crombez, 2011), as illustrated in the case of Marc. As a way of dealing with his pain, Marc's doctor visits may start to take the form of doctor 
shopping, eventually leading to multiple pain interventions and medical risk taking (Eccleston \& Crombez, 2007). Like Marc, many chronic pain patients engage in attempts to find the ultimate cure for pain, often at the expense of other valuable life goals. Paradoxically, it may be the very increase in effort towards the goal of pain control that maintains suffering (Crombez, Eccleston, De Vlieger, Van Damme, \& De Clercq, 2008a). Continuing attempts to control or solve the pain problem when actual control is low is related to fear, worry, catastrophic thinking, and hypervigilance (Crombez, et al., 2008b).

Similarly, goal disengagement is only adaptive when people's appraisal of their control is accurate, and their disengagement from previously desired goals is possible. Disengagement from unattainable goals and re-engagement to new, valuable, and realistic goals is beneficial for well-being and quality of life (Rothermund, 2006; Wrosch et al., 2003). Indeed, pain acceptance has been shown to be associated with successful adaptation to chronic pain (McCracken \& Eccleston, 2003; Viane, Crombez, Eccleston, Poppe, Devulder, Van Houdenhove, \& De Corte, 2003). However, not examined among people with chronic pain is the premature disengagement from valued goals. Coping in this way is not acceptance but premature and unwanted surrender. Perhaps for every patient with chronic pain persisting in unrealistic and unsuccessful attempts at solving the insoluble problem of chronic pain, there is a person surrendering to a narrowed life characterized by minimal goals and avoidance of failure, both of which may fuel depression.

Flexibility in coping seems to be the key to successful adaptation to pain. A crucial question is why patients often persist in coping despite its ineffectiveness and/or its negative consequences. This question has received some research attention. Intriguingly, patients seem to persist in failed attempts to solve their pain problem despite very little belief that a solution exists (De Vlieger, Van den Bussche, Eccleston, \& Crombez, 2006). One reason may be that patients 
believe their pain is a signal of physical harm that should be resolved (Eccleston \& Crombez, 2007). Such a biomedical view on pain is dominant in post-industrial societies, both among lay people (Goubert, Crombez, \& De Bourdeaduhuij, 2004) and health care professionals (Coudeyre, Rannou, Tubach, Baron, Coriat, Brin, Revel, \& Poiraudeau, 2006). According to this view, the experience of pain is reduced to objective harm in the body. A biomedical view of pain, however, may paradoxically hinder recovery and augment the risk for long-term disability (Goubert et al., 2004; Goubert, Crombez, \& Danneels, 2005). Indeed, it is assumed that the biomedical inspired belief that movements may cause injury will narrow attention to the pain and cues of harm and may lead to avoidance of movements that are expected to hurt, eventually ending in more physical and emotional complaints (Leeuw, Goossens, Linton, Crombez, Boersma, \& Vlaeyen, 2007; Vlaeyen \& Linton, 2000). This might explain why those who catastrophize about chronic pain persevere in searching for a solution for pain despite a low level of confidence that such a solution is available (De Vlieger et al., 2006). However, evidence is accumulating that it is not the pain itself and its associated beliefs, but the extent to what pain interferes with daily life that mainly triggers and motivates patients to seek care and pain control (Crombez, Eccleston, Van Damme, Vlaeyen \& Karoly, 2012). In their review on coping with pain, Van Damme et al. (2008) describe a motivational view in which coping with pain is recast as an attempt to restore the pursuit of valued activities and life goals. As such, they suggest a second reason of why some patients may persist in attempts to solve or control their pain. Simply put, any attempt to control pain may emerge for the individual to be able to engage in other daily activities again. Marc, for example, ended up in a pattern of headache flare-ups that consequently triggered him toward medication overuse. When asked about his behavior, he answered: "I know it's a bad thing to overuse my medication, but I have no other option. I have a job to do and I have standards to 
meet". Whenever his headache tended to worsen, he declared to be in desperate need for his medication, which enabled him to go on at work. Conversely, he agreed to withdraw from his medication only when he had less work to do. Although medication overuse seems to have its costs, it also seems to enable patients to retain functioning and achieve valuable goals (Lauwerier et al., 2011). A persistent search for a solution, when there is none available, may only lead to more frustration, distress, and disability (Eccleston \& Crombez, 2007). One has the belief that pain should be resolved to resume daily life and the pursuit of valuable goals. This is also nicely illustrated in a study using Personal Project Analysis (PPA) to assess goals and goal appraisals in individuals with chronic pain (Crombez, Lauwerier, Goubert, \& Van Damme, 2016). Patients scoring high on goal necessity, meaning that they deemed pain control goals to be necessary to achieve other goals, showed negative outcomes.

\section{Theoretical implications}

A motivational or self-regulation perspective on coping may shed new light on several concepts that are central in psychosocial models of pain and suffering. We next discuss these concepts and explain how they can be re-cast from our motivational perspective on coping.

\subsection{Pain catastrophizing}

Catastrophizing about pain has been identified as one of the most important psychological variables in explaining responses to pain in clinical and nonclinical situations. Catastrophizing has been broadly conceived of as an exaggerated negative 'mental set' brought to bear during an actual or anticipated pain experience, and comprises of the aspects of magnification, rumination, and helplessness (Sullivan, Bishop, \& Pivik, 1995). Considerable research has shown that catastrophizing contributes to explaining pain, disability, and associated emotional distress. 
Furthermore, catastrophizing has been associated with an inability to divert attention away from pain-related thoughts and the pain itself, over-prediction of pain, increased pain behavior, increased use of health care services, longer hospital stays, and increased use of medication (Sullivan, Thorn, Haythornthwaite, Keefe, Martin, Bradley, \& Lefebvre, 2001). Given its roots in psychopathology, it is not surprising that catastrophizing is typically considered a maladaptive process. For instance, catastrophizing about bodily sensations is a key factor in cognitivebehavioral models of psychopathology such as panic disorders and hypochondriasis (Salkovskis \& Clark, 1993). However, rather than the kind of "if - then" reasoning about catastrophic outcomes that are typical in psychopathology (Turner \& Aaron, 2001; Rode, Salkovskis, \& Jack, 2001), measures of catastrophizing in the context of pain reflect rumination and feelings of helplessness about being unable to solve or get rid of pain. As such, pain catastrophizing is phenomenologically more similar to worrying and it may, as argued by Eccleston and Crombez (2007), also function to facilitate problem-solving. Whereas worry is basically an adaptive process and may be related to problem-solving, it may become maladaptive in the context of chronic pain, where no immediate solution is available (Aldrich, et al., 2000; Eccleston \& Crombez, 2007). Indeed, it has been shown in chronic pain patients that high pain catastrophizing is associated with more attempts to solve the problem of pain (De Vlieger et al., 2006).

\subsection{Fear-avoidance}

The fear-avoidance (FA) model is one of the most popular psychological theories, describing how acute pain may evolve into a chronic problem. The model has been extensively discussed elsewhere (Vlaeyen \& Linton, 2000). A key factor is the interpretation of pain by the patient. On the one hand, if patients do not interpret the pain as a sign of serious harm, they are likely to quickly resume physical activity, increasing the chance of fast recovery. On the other 
hand, a tendency to catastrophize about pain is assumed to provide fertile ground for the development of fear of pain and re-injury, leading to misbeliefs about the potentially harmful consequences of movement, as a result of which a pattern of gradual avoidance of physical activity will be installed. This is likely to put them at risk for the development of a chronic pain problem.

Because the main principles of the FA model are grounded in the cognitive-behavioral treatment of phobia and anxiety disorders, there is often a strong emphasis on the idea that patients have excessive negative cognitions or irrational beliefs about pain and movement (Crombez et al., 2012). This idea is also found in instruments assessing fear of (re)injury and movement, such as the Tampa Scale for Kinesiophobia (Kori, Miller, \& Todd, 1990). However, the evidence base for the idea that such beliefs are "erroneous", typical for chronic pain patients, and the result of psychopathology, is far from convincing (Barke, Baudewig, Schmidt-Samoa, Dechent, \& Kröner-Herwig, 2012; Crombez et al, 2012; Pincus, Smeets, Simmonds, \& Sullivan, 2010). As a matter of fact, such beliefs are quite common, also in the general population (Goubert et al., 2004; Houben, Ostelo, Vlaeyen, Wolters, Peters, \& Stomp-van den Berg, 2005) and even among health care providers (Bishop, Foster, Thomas, \& Hay, 2008; Coudeyre et al., 2006; Houben et al., 2005).

In line with the plea for a re-positioning of the fear-avoidance model from a motivational perspective (Crombez et al., 2012; Van Damme \& Kindermans, 2015), we propose that a motivational perspective on coping may contribute to a better understanding of fear-avoidance behavior. It has been argued that avoidance may be one form of problem solving when pain interferes with pursuit of valued goals. Specifically, one may temporarily stop performing physical activities to get better, so that goals can be pursued later on. Or, one may stop 
performing certain tasks to avoid feelings of frustration or social evaluation when goal attainment is unsuccessful. This is, however, not without costs, because avoiding pain often halts the pursuit of valued goals.

\subsection{Persistence/endurance}

Another way of coping with goal interference by pain is increasing effort to accomplish the goal (i.e., goal persistence). One will simply try harder, and if this is unfeasible, alternative means to reach the disrupted goal will be sought. Often, this will be accompanied by attempts to ignore pain and suppress pain-related thoughts (i.e., endurance). As will be discussed in the next section, pursuing a valued goal is also likely to inhibit attention to pain, which may result in reduced pain sensitivity (Van Damme et al., 2010; Verhoeven et al., 2010; Legrain, Crombez, Verhoeven, \& Mouraux, 2011; see also chapter on attention xxxxxx).

Research has shown that subgroups of chronic pain patients persist in their activities despite pain (Crombez, Vervaet, Lysens, Baeyens, \& Eelen, 1998; Hasenbring and Verbunt, 2010). According to the fear-avoidance model, persistence of physical activity despite pain may help recovery and prevent chronification of the problem (Vlaeyen \& Linton, 2000). Because persistence may promote more successful goal attainment, it may be beneficial for patients' wellbeing. However, excessive task persistence despite severe pain may become dysfunctional in the long term, possibly resulting in a range of physiological problems (see also chapter $\mathrm{x}$ on stress and pain), and that it may even predict less successful rehabilitation (see Hasenbring, Marienfeld, Kuhlendahl, \& Soyka, 1994; Hasenbring, Plaas, Fischbein, \& Willburger, 2006). However, more systematic research on the beneficial as well as adverse effects of long term persistence is warranted. Specifically, in current models, persistence is considered a relatively stable characteristic of patients. Considering the motivational context may be helpful in better 
understanding patterns of persistence behavior, as well as uncover where the boundaries are between adaptive and maladaptive persistence (Van Damme, 2015).

\subsection{Pain-related attention}

Excessive attention to pain-related information, often referred to as hypervigilance or attentional bias, is a key process in several theoretical models of pain perception and disability (Crombez, Van Damme, \& Eccleston, 2005; Todd, Sharpe, Johnson, Nicholson Perry, Colagiuri, \& Dear, 2015; Sullivan et al., 2001; Vlaeyen \& Linton, 2000, see also chapter on attention xxxxxx). The amount of attention allocated to pain and pain-related information is typically seen as a stable individual characteristic. However, although a recent meta-analysis suggested that chronic pain patients allocate more attention to pain-related information than do healthy controls, this effect seems to be subtle, and is characterized by a great deal of variability (Crombez, Van Ryckeghem, Eccleston, \& Van Damme, 2013). Missing is the role of contextual factors, such as the goals currently pursued. We argue that pain-related attention always should be considered within a context of goal pursuit (Eccleston \& Crombez, 1999; Van Damme et al., 2010; see also Chapter 7). According to motivational models, the allocation of attention is determined by the activation of goals (Legrain, Van Damme, Eccleston, Davis, Seminowicz, \& Crombez, 2009; Van Damme et al., 2010). Goal-relevant information is given priority and goal-irrelevant information is inhibited (Goschke \& Dreisbach, 2008; Shah, Friedman, \& Kruglanski, 2002). From this perspective, two largely unexplored theoretical assumptions are introduced. First, when pain occurs during the pursuit of a certain goal, it may unintentionally capture attention although it is not relevant for the goal. Whether such unintentional attentional capture happens is not only dependent upon the characteristics of the pain but also on the characteristics of the focal goal. If one is strongly committed to the focal goal, effort will be increased and attention will be 
shielded so that distraction by pain is minimized. Second, attention to pain and pain-related information might be driven by a focal goal related to pain. Attentional processing of pain information will be particularly enhanced when the focal goal is related to pain management, for example, if one attempts to control or solve the pain. In sum, different coping trajectories may result in different amounts of attention to pain. Some empirical support has been found for this idea using experimental pain in healthy volunteers. Specifically, it has been shown that strong engagement in a non-pain goal reduced allocation of attention to pain and pain-related information (Schrooten et al., 2012; Verhoeven et al., 2010). Similarly, pursuing pain-related goals such as avoidance of pain increased attention to pain-related cues (Notebaert, Crombez, Vogt, De Houwer, Van Damme, \& Theeuwes, 2011) and to the location on the body where pain is expected (Durnez \& Van Damme, 2015).

\subsection{Acceptance}

When goal maintenance becomes increasingly difficult and frustrating, a more adaptive coping response may be the flexible adjustment of unattainable goals. A number of selfregulation theories have argued for the beneficial effect and protective role of such mode of coping on quality of life in the context of ageing and illness (Brandtstädter \& Rothermund, 2002; Heckhausen, Wrosch, \& Schulz, 2010; Rasmussen et al., 2006; Wrosch et al., 2003). Applied to chronic pain, attempts to control or solve the pain problem may have repeatedly failed, and goal pursuit may have become increasingly problematic. When goals have become unrealistic as the result of pain, patients might need to shift focus, by disengaging from unfruitful goal pursuit and reengaging in other valuable but realistic goals (Van Damme et al., 2008). In chronic pain patients, there is often an unsuccessful search for control over the pain problem, and as result, pain may dominate life at the cost of the pursuit of valued goals. When this is the case, patients 
might benefit more from letting go the goal of finding a definitive solution for the pain problem (Eccleston \& Crombez, 2007). This resembles the idea of acceptance, which has been defined as halting the dominant search for a definitive cure for pain and re-orientating one's attention toward positive everyday activities and other rewarding aspects of life (McCracken \& Eccleston 2003, 2005; Wicksell, Olsson, \& Haeyes, 2011; McCracken, Carson, Eccleston, \& Keefe, 2004; see also chapter on acceptance and psychological flexibility xxxxx). An extensive body of research has demonstrated that acceptance reduces the negative effects of pain on both mental and physical wellbeing (Viane et al., 2003; McCracken \& Eccleston, 2005). Nevertheless, the conceptualization and operationalization of acceptance has been somewhat confusing (Lauwerier, Caes, Van Damme, Goubert, Rosseel, \& Crombez, 2015), and a reframing within a goal pursuit and self-regulation perspective may provide theoretical ground for further research and clinical applications.

\section{Clinical implications: Coping as goal management}

A motivated coping perspective leads to new avenues of investigation in the field of pain treatment. Promoting effective adaptation to chronic pain will require, we suspect, the assessment of motivated behavior in context. Assessing the dynamic interplay of problem appraisal and coping attempts will be a significant advance. Many of our methods for appraising coping are based on self-reports of tendencies, habits, or preferences. Coping is typically characterized as a behavioral style or a stable characteristic. Rarely sampled is the moment to moment variability in coping in which people experiment, persist, appraise, reappraise, receive feedback, ignore consequences, seek new tactics, and stop old strategies. In short, many decisions are often made in the moment. 
Cognitive behavior therapies for people with chronic pain are replete with techniques and strategies that are aimed at promoting flexible problem appraisal and solving, and techniques for countering avoidance behavior (Vlaeyen, de Jong, Geilen, Heuts, \& van Breukelen, 2002). The efficacy of therapeutic approaches aimed at increasing functional ability of patients, such as exposure and graded activity, might be optimized by embedding them in a motivational approach in which the goals and values of patients are considered (McCracken \& Yang, 2006). Recent developments have focused on techniques of acceptance and commitment therapy that promote a willingness to experience adversity and an engagement with valued activities despite adversity (Vowles \& McCracken, 2008; see also McCracken \& Scott in the present volume). Flexibility in one's responses, depending upon context and goals, is needed. This requires a good balance between avoidance and persistence behavior. Another avenue is in the use of implementation intentions and coping planning techniques inspired by goal enactment theories (Schrooten, Vlaeyen, \& Morley, 2012). These are relevant both for the pursuit of treatment goals and for coping with pain's interference in daily life goal pursuit.

\section{Conclusion}

We summarize the key messages from this chapter. First, we assert that a definitive conclusion on the best ways to cope with pain is impossible, and that coping responses can be either adaptive or maladaptive depending upon the context. We have argued that a motivational perspective on coping, addresses questions hitherto largely left unanswered: what exactly does the patient wants to achieve (see three adaptive functions of Skinner et al., 2003) and how does the patient want to achieve this (self-regulatory processes). Taking the building blocks of this perspective further, we have introduced a model of coping with pain, which differentiates 
between 3 coping routes: (1) goal persistence, (2), problem solving, and (3) goal adjustment. It may be helpful to categorize coping responses based upon these coping routes, rather than to seek to differentiate between coping responses based upon descriptive or structural features. Furthermore, we have shown that a motivational view on coping with pain may recast some key processes in the pain literature such as catastrophizing, fear-avoidance, endurance, hypervigilance, and acceptance. Finally, our motivational view holds promises to further refine existing pain management approaches, as exemplified by the other chapters of this book.

\section{References}

Abraham, C. \& Sheeran, P. (2000). Understanding and changing health behaviour: From health beliefs to self-regulation. In P. Norman, C. Abraham \& M. Conner (Eds.), Understanding and Changing Health Behaviour: From health beliefs to self-regulation (pp. 3-24). Amsterdam: Harwood.

Affleck, G., Tennen, H., Keefe, F.J., Lefebvre, J.C., Kashikar-Zuck, S., Wright, K., et al. (1999). Everyday life with osteoarthritis or rheumatoid arthritis: independent effects of disease and gender on daily pain, mood, and coping. Pain, 83, 601-609.

Affleck, G., Tennen, H., Zautra, A., Urrows, S., Abeles, M., \& Karoly, P. (2001). Women's pursuit of personal goals in daily life with fibromyalgia: a value-expectancy analysis. Journal of Consulting and Clinical Psychology, 69, 587-596.

Aldrich, S., Eccleston, C., \& Crombez, G. (2000). Worrying about chronic pain: vigilance to threat and misdirected problem solving. Behaviour Research and Therapy, 38, 457-470. 
Barke, A., Baudewig, J., Schmidt-Samoa, C., Decent, P., \& Kröner-Herwig, B. (2012). Neural correlates of fear of movement in high and low fear-avoidant chronic low back pain patients: an event-related fMRI study. Pain, 153, 540-552.

Bishop, A., Foster, N.E., Thomas, E., \& Hay, E.M. (2008). How does the self-reported clinical management of patients with low back pain relate to the attitudes and beliefs of health care practitioners? A survey of UK general practitioners and physiotherapists. Pain, 135, 187-195.

Brandtstädter, J., \& Rothermund, K. (2002). The life-course dynamics of goal pursuit and goal adjustment: A two-process framework. Developmental Review, 22, 117-150.

Brown, G.K., \& Nicassio, P.M. (1987). Development of a questionnaire for the assessment of active and passive coping strategies in chronic pain patients. Pain, 31, 53-64.

Buckelew, S.P., Parker, J.C., Keefe, F.J., Deuser, W.E., Crews, T.M., Conway Kay, D.R., et al. (1994). Self-efficacy and pain behavior among subjects with fibromyalgia. Pain, 59, 37784.

Cameron, L. D., \& Leventhal, H. (Eds.) (2003). The self-regulation of health and illness behaviour. London and New York: Routledge.

Carroll, L.J., Cassidy, J.D., \& Cote, P. (2006). The role of pain coping strategies in prognosis after whiplash injury: Passive coping predicts slowed recovery. Pain, 124, 18-26.

Carver, C. S., \& Scheier, M. F. (1982). Control theory: A useful conceptual framework for personality-social, clinical, and health psychology. Psychological Bulletin, 92, 111-135.

Carver, C., \& Scheier, M. (1998). On the self-regulation of behavior. Cambridge, England: Cambridge University Press. 
Christiansen, S., Oettingen, G., Dahme, B., \& Klinger, R. (2010). A short goal-pursuit intervention to improve physical capacity: A randomized clinical trials in chronic back pain patients. Pain, 149, 444-152.

Claes, N., Kairos, K., Meulders, A., Crombez, G., \& Vlaeyen, J.W.S. (2014). Competing goals attenuate avoidance behavior in the context of pain. Journal of Pain, 15, 1120-1129.

Coudeyre, E., Rannou, F., Tubach, F, Baron, G., Coriat, F., Brin, S., et al. (2006). General practitioners' fear-avoidance beliefs influence their management of patients with low back pain. Pain, 124, 330-337.

Coyne, J.C., \& Racioppo, M.W. (2000). Never the Twain shall meet? Closing the gap between coping research and clinical intervention research? American Psychologist, 55, 655-664.

Crombez, G., Eccleston, C., Baeyens, F., \& Eelen, P. (1996). The disruptive nature of pain: An experimental investigation. Behaviour Research and Therapy, 34, 911-918.

Crombez, G., Eccleston, C., De Vlieger, P., Van Damme, S., \& De Clercq, A. (2008a). Is it better to have controlled and lost than never to have controlled at all? An experimental investigation of control over pain. Pain, 137, 631-639.

Crombez, G., Eccleston, C., Van Damme, S., Vlaeyen, J.W.S., \& Karoly, P. (2012). The fearavoidance model of chronic pain: the next generation. Clinical Journal of Pain, 28, 475483.

Crombez, G., Eccleston, C., Van Hamme, G. \& De Vlieger, P. (2008b). Attempting to solve the problem of pain: A questionnaire study in acute and chronic pain patients. Pain, 137, 3, $556-563$.

Crombez, G., Lauwerier, E., Goubert, L., \& Van Damme, S. (2016). Goal pursuit in individuals with chronic pain: A personal project analysis. Frontiers in Psychology, 7, 966. 
Crombez, G., Van Damme, S., \& Eccleston, C. (2005). Hypervigilance to pain: an experimental and clinical analysis. Pain, 116, 4-7.

Crombez, G., Van Ryckeghem, D.M.L., Eccleston, C., \& Van Damme, S. (2013). Attentional bias to pain-related information: a meta-analysis. Pain, 154, 497-510.

Crombez, G., Vervaet, L., Lysens, R., Baeyens, F. \& Eelen, P. (1998). Avoidance and confrontation of painful, back straining movements in chronic back pain patients. Behavior Modification, 22, 62-77.

de Ridder, D., \& de Wit, J. (2006). Self-regulation in health behavior. Chichester, UK: John Wiley \& Sons.

De Vlieger, P., Van den Bussche, E., Eccleston, C., \& Crombez, G. (2006). Finding a solution to the problem of pain: Conceptual formulation and the development of the Pain Solutions Questionnaire (PaSol). Pain, 123, 285-293.

Durnez, W., \& Van Damme, S. (2015). Trying to fix a painful problem: The impact of pain control attempts on the attentional prioritization of a threatened body location. The Journal of Pain, 16, 135-143.

Eccleston, C., \& Crombez, G. (1999). Pain demands attention: A cognitive-affective model of the interruptive function of pain. Psychological Bulletin, 125, 356-366.

Eccleston, C., \& Crombez, G. (2007). Worry and chronic pain: A misdirected problem solving model. Pain, 132, 233-236.

Esteve-Zaragaza, R., Ramírez-Maestre, C., \& López-Martínez, A.E. (2007). Adjustment to chronic pain: The role of pain acceptance, coping strategies, and pain-related cognitions. Annals of Behavioral Medicine, 33, 179-188. 
Folkman, S., Lazarus, R.S., Gruen, R.J., \& DeLongis, A. (1986). Appraisal, coping, health status, and psychological symptoms. Journal of Personality and Social Psychology, 50, 571-579.

Fordyce, W.E. (1976). Behavioral methods for chronic pain and illness. St Louis, MO: The C.V. Mosby Company.

Gollwitzer, P.M. (1996). The volitional benefits of planning. In P.M. Gollwitzer \& J.A. Bargh (Eds.), The Psychology of Action: Linking cognition and motivation to behavior (pp. 287312). New York: Guilford.

Gollwitzer, P.M. (1999). Implementation intentions: Strong effects of simple plans. American Psychologist, 54, 493-503.

Gollwitzer, P. M., \& Sheeran, P. (2006). Implementation intentions and goal achievement: A meta-analysis of effects and processes. Advances in Experimental Social Psychology, 38, 69-119.

Goschke, T., \& Dreisbach, G. (2008). Conflict-triggered goal shielding: Response conflicts attenuate background monitoring for prospective memory cues. Psychological Science, $19,25-32$

Goubert, L., Crombez, G., \& Danneels, L. (2005). The reluctance to generalize corrective experiences in chronic low back pain patients: a questionnaire study of dysfunctional cognitions. Behaviour Research and Therapy, 43, 1055-1067.

Goubert, L., Crombez, G., \& De Bourdeaudhuij, I. (2004). Low back pain, disability and back pain myths in a community sample: prevalence and interrelationships. European Journal of Pain, 8, 385-394. 
Gutièrrez, O., Luciano, C., Rodriguez, M., \& Fink, B.C. (2004). Comparison between an acceptance-based and a cognitive-control-based protocol for coping with pain. Behavior Therapy, 35, 767-783.

Hasenbring, M., Marienfield, G., Kuhlendahl, D., \& Soyka, D. (1994). Risk factors of chronicity in lumbar disc patients: a prospective investigation of biologic, psychologic, and social predictors of therapy outcome. Spine, 19, 2759-2765.

Hasenbring, M.I., Plaas, H., Fishbein, B., \& Willburger, R. (2006). The relationship between activity and pain in patients 6 months after lumbar disc surgery: Do pain-related coping modes act as moderator variables? European Journal of Pain, 10, 701-709.

Hasenbring, M.I., \& Verbunt, J.A. (2010). Fear-avoidance and endurance-related responses to pain: New models of behavior and their consequences for clinical practice. Clinical Journal of Pain, 26, 747-753.

Heckhausen, J., Wrosch, C., \& Schulz, R. (2010). A motivational theory of life-span development. Psychological Review, 117, 32-60.

Hobfoll, S.E. (1988). The ecology of stress. New York: Hemisphere Publishing Corporation, $360 \mathrm{p}$.

Houben, R.M., Ostelo, R.W., Vlaeyen, J.W, Wolters, P.M., Peters, M., \& Stomp-van den Berg, S.G. (2005). Health care providers' orientations towards common low back pain predict perceived harmfulness of physical activities and recommendations regarding return to normal activity. European Journal of Pain, 9, 173-183.

Jensen, M.P., \& Karoly, P. (1991). Control beliefs, coping efforts, and adjustment to chronic pain. Journal of Consulting and Clinical Psychology, 59, 431-438. 
Karoly, P. (1993). Mechanisms of self-regulation: a systems view. Annual Review of Psychology, $44,23-52$.

Karoly, P., \& Ruehlman, L.S. (2007). Psychosocial aspects of pain-related life task interference: an exploratory analysis in a general population sample. Pain Medicine, 8, 563-572.

Karsorp, P.A., Geenen, R., Kroese, F.M., \& Vlaeyen, J.W. (2016). Turning pain into cues for goal-directed behavior: Implementation intentions reduce escape-avoidance behavior on a painful task. Journal of Pain, 17, 499-507.

Keefe, F.J., Rumble, M.E., Scipio, C.D., Giordano, L.A., \& Perri, L.M. (2004). Psychological aspects of persistent pain: Current state of the science. Journal of Pain, 5, 195-211.

Koleck, M., Mazaux, J.M., Rascle, N., \& Bruchon-Schweitzer, M. (2006). Psycho-social factors and coping strategies as predictors of chronic evolution and quality of life in patients with low back pain: a prospective study. European Journal of Pain, 10, 1-11.

Kori, S.H., Miller, R.P., \& Todd, D.D. (1990). Kinesiophobia: A new view of chronic pain behavior. Pain Management, 1,35-43.

Lauwerier, E., Caes, L., Van Damme, S., Goubert, L., Rosseel, Y., \& Crombez, G. (2015).

Acceptance: what's in a name? A content analysis of acceptance instruments in individuals with chronic pain. The Journal of Pain, 16, 306-317.

Lauwerier, E., Paemeleire, K., Van Damme, S., Goubert, L., \& Crombez, G. (2011). Medication use in patients with Migraine and Medication-Overuse Headache: on the role of problem solving style and attitudes about pain medication. Pain, 152, 1334-1339.

Lazarus, R.S. (1991). Emotion and adaptation. New York: Oxford University Press.

Lazarus, R.S., \& Folkman, S. (1984). Stress, appraisal and coping. New York: Springer Publishing Company. 
Lazarus, R.S., \& Launier, R. (1978). Stress-related transactions between person and environment. In L.A. Pervin \& M. Lewis (eds.), Perspectives in Interactional Psychology. New York: Plenum, 287-327.

Leeuw, M., Goossens, M.E.J.B., Linton, S.J., Crombez, G., Boersma, K. , \& Vlaeyen, J.W.S. (2007). The fear-avoidance model of musculoskeletal pain: current state of scientific evidence. Behavioral Medicine, 30, 1, 77-94.

Legrain, V., Crombez, G., Verhoeven, K., \& Mouraux, A. (2011). The role of working memory in the attentional control of pain. Pain, 152, 453-459.

Legrain, V., Van Damme, S., Eccleston, C., Davis, K. D., Seminowicz, D. A., \& Crombez, G. (2009). A neurocognitive model of attention to pain: Behavioural and neuroimaging evidence. Pain, 144, 230-232.

Leventhal. H., Meyer, D., \& Nerenz, DR. (1980). The common sense representation of illness danger. In S. Rachman (Ed.). Contributions to Medical Psychology (vol. 2, pp.7-30). New York Pergamon Press.

López-Martínez, A.E., Esteve-Zaragaza, R., \& Ramírez-Maestre, C. (2008). Perceived social support and coping responses are independent variables explaining pain adjustment among chronic pain patients. Journal of Pain, 9, 373-379.

McCracken, L.M., Carson, J.W., Eccleston, C., \& Keefe, F.J. (2004). Acceptance and change in the context of chronic pain. Pain, 109, 4-7.

McCracken, L.M., \& Eccleston, C. (2003). Coping or acceptance: what to do about chronic pain? Pain, 105, 197-204.

McCracken, L.M., \& Eccleston, C. (2005). A prospective study of acceptance of pain and patient functioning with chronic pain. Pain, 118, 164-169. 
McCracken, L.M., \& Yang, S. (2006). The role of values in a contextual cognitive-behavioral approach to chronic pain. Pain, 123, 137-145.

Morley, S., Davies, C., \& Barton, S. (2005). Possible selves in chronic pain: self-pain enmeshment, adjustment and acceptance. Pain, 115, 84-94.

Nicassio, P.M., Schuman, C., Radojevic, V., \& Weisman, M.H. (1999). Helplessness as a mediator of health status in fibromyalgia. Cognitive Therapy and Research, 23, 181-196.

Notebaert, L., Crombez, G., Vogt, J., De Houwer, J., Van Damme, S., \& Theeuwes, J. (2011). Attempts to control pain prioritize attention towards signals of pain: An experimental study. Pain, 152, 1068-1073.

Pincus, T., Smeets, R.J.E.M., Simmonds, M.J., \& Sullivan, M.J. (2010). The Fear Avoidance Model disentangled: Improving Clinical Utility of the Fear Avoidance Model. Clinical Journal of Pain, 26, 739-746.

Rasmussen, H. N., Wrosch, C., Scheier, M. F., \& Carver, C. S. (2006). Self-regulation processes and health: The importance of optimism and goal adjustment. Journal of Personality, 74, $1721-1747$.

Reid, G.J., Golbert, C.A., \& McGrath, P.J. (1998). The Pain Coping Questionnaire: preliminary validation. Pain, 76, 83-96.

Rode, S., Salkovskis, P.M., \& Jack, T. (2001). An experimental study of attention, labeling and memory in people suffering from chronic pain. Pain, 94, 193-203.

Roth, S., \& Cohen, L.J. (1986). Approach, avoidance, and coping with stress. American Psychologist, 41, 813-819. 
Rothermund, K. (2006). Hanging on and letting go in the pursuit of health goals: Psychological mechanisms to cope with a regulatory dilemma. In D. De ridder, \& J. De Wit (Eds.), Self Regulation in health behaviour. Chichester, UK: Wiley (p. 217-241).

Rusu, A.C., \& Hasenbring, M. (2008). Multidimensional Pain Inventory derived classifications of chronic pain: evidence for maladaptive pain-related coping within the dysfunctional group. Pain, 134, 80-90.

Salkovskis, P.M., \& Clark, D.M. (1993). Panic disorder and hypochondriasis. Advances in Behavior Research and Therapy, 15, 23-48.

Schrooten, M., Van Damme, S., Crombez, G., Peters, M., Vogt, J., \& Vlaeyen, J.W.S. (2012). Nonpain goal pursuit inhibits attentional bias to pain. Pain, 153, 1180-1186.

Schrooten, M.G., Vlaeyen, J.W., \& Morley, S. (2012). Psychological interventions for chronic pain: reviewed within the context of goal pursuit. Pain Management, 2, 141-150.

Schwarzer, R. (2008). Modeling health behavior change: How to predict and modify the adoption and maintenance of health behaviors. Applied Psychology: An International Review, 57, $1-29$.

Shah, J.Y., Friedman, R., Kruglanski, A.W. (2002). Forgetting all else: On the antecedents and consequences of goal shielding. Journal of Personality and Social Psychology, 83, 12611280.

Skinner, E.A., Edge, K., Altman, J., \& Sherwood, H. (2003). Searching for the structure of coping: a review and critique of category systems for classifying ways of coping. Psychological Bulletin, 129, 316-269. 
Sniehotta, F. F., Scholz, U., \& Schwarzer, R. (2006). Action plans and coping plans for physical exercise: A longitudinal intervention study in cardiac rehabilitation. British Journal of Health Psychology, 11, 23-37.

Sniehotta, F. F., Schwarzer, R., Scholz, U., \& Schüz, B. (2005). Action planning and coping planning for long-term lifestyle change: Theory and assessment. European Journal of Social Psychology, 35, 565-576.

Steed, L.G. (1998). A critique of coping scales. Australian Psychologist, 33, 193-202.

Sullivan, M.J.L., Bishop, S.R., \& Pivik, J. (1995). The Pain Catastrophizing Scale: Development and validation. Psychological Assessment, 7, 524-532.

Sullivan, M.J.L., Thorn, B., Haythornthwaite, J.A., Keefe, F., Martin, M., Bradley, L.A., et al. (2001). Theoretical perspectives on the relation between catastrophizing and pain. Clinical Journal of Pain, 17, 52-64.

Taylor, S.E., Klein, L.C., Lewis, B.P., Gruenewald, T.L., Gurung, R.A.R., \& Updegraff, J.A. (2000). Biobehavioral responses to stress in females: Tend-and-befriend, not fight-orflight. Psychological Review, 107, 411-429.

Todd, J., Sharpe, L., Johnson, A., Nicholson, P.K., Colagiuri, B., \& Dear, B.F. (2015). Towards a new model of attentional biases in the development, maintenance, and management of pain. Pain, 156, 1589-1600.

Tunks, E., \& Bellissimo, A. (1988). Coping with the coping concept - a brief comment. Pain, 34, $171-174$

Turner, J.A., \& Aaron, L.A. (2001). Pain-related catastrophizing: What is it? Clinical Journal of Pain, 17, 65-71. 
Van Damme, S. (2015). Avoidance and persistence: Capacity or motivation? Clinical Journal of Pain, 31, 843-844.

Van Damme, S., Crombez, G., \& Eccleston, C. (2008). Coping with pain: a motivational perspective. Pain, 139, 1-4.

Van Damme, S., \& Kindermans, H. (2015). A self-regulation perspective on avoidance and persistence behaviour in chronic pain: new theories, new challenges? Clinical Journal of Pain, 31, 115-122.

Van Damme, S., Legrain, V., Vogt, J., \& Crombez, G. (2010). Keeping pain in mind: a motivational account of attention to pain. Neuroscience and Biobehavioral Reviews, 34, 204-213.

Van Damme, S., Van Ryckeghem, D., Wyffels, F., Van Hulle, L., \& Crombez, G. (2012). No gain without pain: pursuing a competing goal inhibits avoidance behaviour. Pain, 153, 800-804.

Verhoeven, K., Crombez, G., Eccleston, C., Van Ryckeghem, D.M.L., Morley, S, \& Van Damme, S. (2010). The role of motivation in distracting attention away from pain: An experimental investigation. Pain, 149, 229-234.

Viane, I., Crombez, G., Eccleston, C., Poppe, C., Devulder, J., Van Houdenhove, B., et al. (2003). Acceptance of pain is an independent predictor of mental well-being in patients with chronic pain: empirical evidence and reappraisal. Pain, 106, 65-72.

Vlaeyen, J.W.S., de Jong, J., Geilen, M., Heuts, P.H.T.G., \& van Breukelen, G. (2002). The treatment of fear of movement/(re)injury in chronic low back pain: Further evidence on the effectiveness of exposure in vivo. Clinical Journal of Pain, 18, 251-261. 
Vlaeyen, J.W.S., \& Linton, S.J. (2000). Fear-avoidance and its consequences in chronic musculoskeletal pain: a state of the art. Pain, 85, 317-332.

Vohs, K. D., \& Baumeister, R. F. (2004). Understanding self-regulation: An introduction. In R. F. Baumeister \& K. D. Vohs (Eds.), Handbook of Self-Regulation: Research, Theory, and Application (pp. 3-10). New York, NY: Guilford Press.

Vowles, K.E., \& McCracken, L.M. (2008). Acceptance and values-based action in chronic pain: A study of treatment effectiveness and process. Journal of Consulting and Clinical Psychology, 76, 397-407.

Wicksell, R.K., Olsson, G.L., \& Hayes, S.C. (2011). Psychological flexibility as a mediator of improvement in Acceptance and Commitment Therapy for patients with chronic pain following whiplash. European Journal of Pain, 14, 1059-1067.

Wrosch, C., Scheier, M.F., Miller, G.E., Schulz, R., \& Carver, C.S. (2003). Adaptive selfregulation of unattainable goals: goal disengagement, goal reengagement, and subjective well-being. Personality and Social Psychology Bulletin, 29, 1494-1508. 


\section{Figure captions}

Fig. 1. Motivational model of coping.

The model starts with the interruption of goal-directed behavior by pain, resulting in growing discrepancy between the outcome of goal pursuit and what is aspired. This discrepancy results in negative affect, which triggers three possible coping responses: (1) goal persistence, meaning that patients are motivated to stay committed to earlier life goals and performance standards, (2) problem-solving, when pain control and the search for a solution are prioritized over other personal goals, or (3) goal adjustment, referring to either maintaining the current goal in place, but at a lower goal standard, or reducing effort resulting in the current goal being abandoned (disengagement) and replaced by an alternative goal.

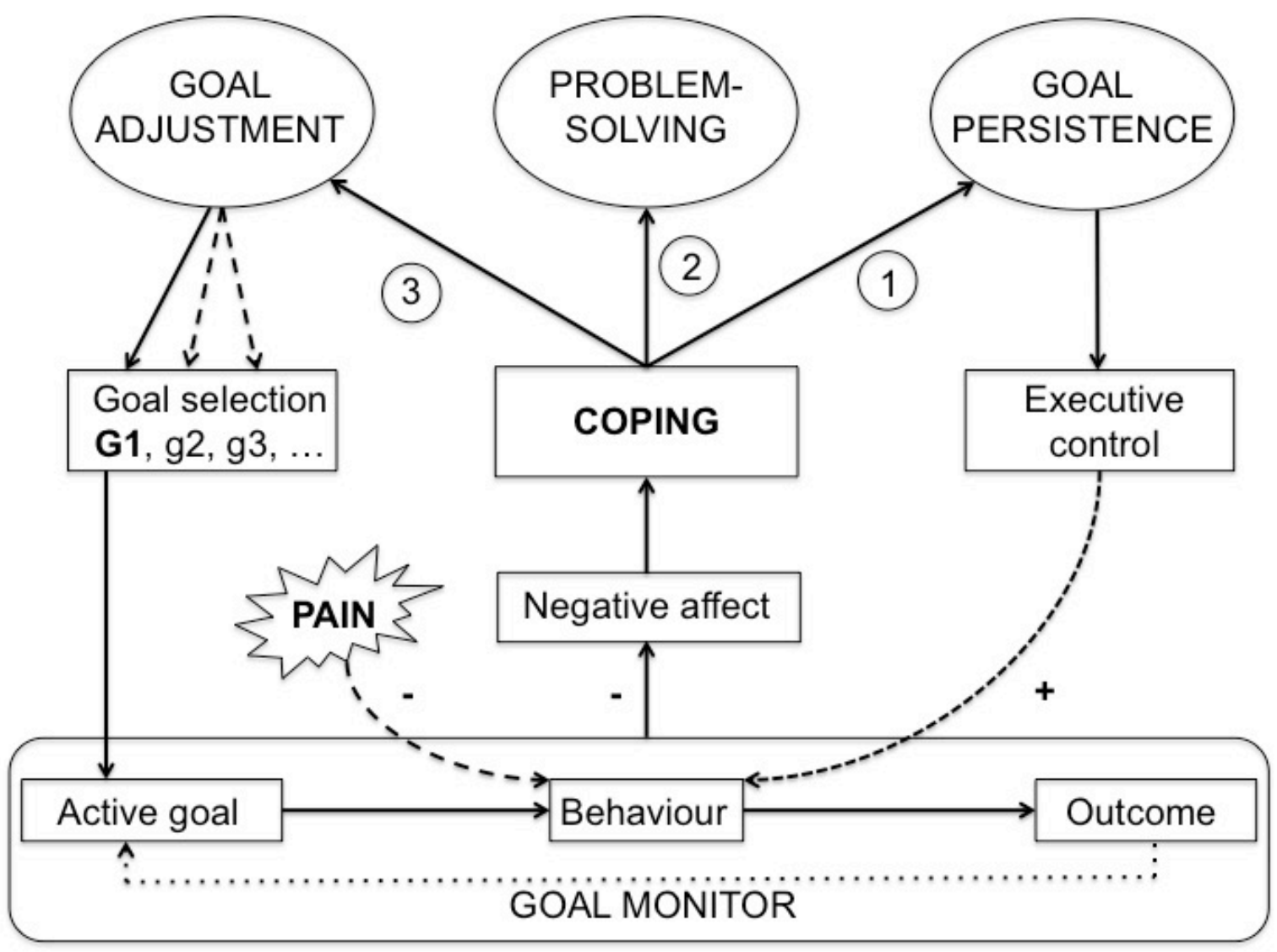




\section{Box 13.1: Three examples of chronic pain patients: Louise, Marc, and Ann}

\section{Case Louise (39-year-old female)}

Since a few years, Louise started to suffer from recurrent back back pain episodes. In her job she is very ambitious and currently aims for a promotion. Therefore, she works hard and tries to ignore the pain. Sometimes this works, but sometimes she notices that the pain starts to interfere with her work, and that she cannot go on, she rests and as soon as she feels better, she compensates for the lost time by working some extra hours. Some days are good, but other days she really suffers a lot, and the last couple of months the amount of bad days has been increasing...

\section{Case Marc (45 year-old male)}

Marc is a high school teacher who has been suffering from severe headache attacks for a few years now. He has consulted several general practitioners to get pain medication subscribed. This way he has been able to function at work most of the time. Recently, the headache attacks have increased in intensity and frequency. He was referred to tertiary care, and after a few examinations, he was diagnosed with Medication-Overuse Headache (MOH). After successful withdrawal from his medication and consecutive improvement, he again experienced significant episodes of headache over the next months. Eventually, he relapsed into the same pattern of medication overuse. Asked about his medication use, he explains that it is the only way to be able to go on with life...

\section{Case Ann (47 year-old female)}

Ann started to complain of widespread pain, and this has gradually developed into a chronic problem. She has always been sporting, and especially liked to go spinning with her friends. Because of the pain this has become more and more difficult, and eventually she stopped doing it. After a while she invited her friends for some other activities. For example, they joined a walking club, and they often go together for a walk now. Sometimes she still misses spinning, and she still feels disappointed that she gave this up. However, other days she is happy that she found another activity to do together with her friends. 